Rev. Int. Contam. Ambie. 36 (1) 7-20, 2020

DOI: $10.20937 /$ RICA.2020.36.53034

\title{
DECOLORACIÓN SONOQUÍMICA SINÉRGICA DEL ANARANJADO DE METILO UTILIZANDO TRICLOROMETANO EN DOS REACTORES ULTRASÓNICOS
}

Synergic sonochemical decoloration of methyl orange using trichloromethane in two ultrasonic reactors

\author{
Luis Alfredo KIEFFER ${ }^{1 *}$, Patricia Mónica DE LA SIERRA², María CLARET ${ }^{2}$ \\ Carlos MARTÍN ${ }^{2}$ y Estefanía LEIZ ${ }^{1}$
}

\author{
${ }^{1}$ Fundación para la Promoción y Desarrollo Tecnológico del Litoral, Güemes 3450, 3000 Santa Fe, Argentina \\ ${ }^{2}$ Facultad de Ingeniería y Ciencias Hídricas, Universidad Nacional del Litoral, Ciudad Universitaria, Paraje El \\ Pozo, km 472.4 Ruta 1, 3000 Santa Fe, Argentina \\ *Autor parea correspondencia: luiskieffer71@gmail.com
}

(Recibido: diciembre 2017; aceptado: octubre 2018)

Palabras clave: tratamiento de aguas, ultrasonido, colorante azoico

\section{RESUMEN}

Se estudia la decoloración del anaranjado de metilo (AM), un colorante azoico con propiedades mutagénicas. Se analiza la acción del triclorometano $\left(\mathrm{HCCl}_{3}\right)(\mathrm{TM})$ como agente sinérgico, utilizando un reactor ultrasónico por lotes y otro continuo. Se demuestra que la decoloración sonoquímica del AM es ampliamente favorecida por la adición de bajas concentraciones de $\mathrm{HCCl}_{3}$. En el caso del reactor por lotes, se obtuvieron decoloraciones del 17 y $98 \%$ sin y con triclorometano, y las constantes cinéticas respectivas fueron estadísticamente diferentes. En el reactor continuo se alcanzaron decoloraciones del $7 \%$ y superiores al $80 \%$ sin y con TM, respectivamente, una vez que el reactor entró en estado estacionario.

Key words: water treatment, ultrasound, azo dyer

\begin{abstract}
The discoloration of methyl orange (AM), an azo dyer with mutagenic properties, is studied. The action of trichloromethane $\left(\mathrm{HCCl}_{3}\right)(\mathrm{TM})$ is analyzed as a synergistic agent, using batch and continuous ultrasonic reactors. It is demonstrated that the sonochemical discoloration of AM is widely favored by the addition of low concentrations of $\mathrm{HCCl}_{3}$. In the case of the batch reactor, discolorations of 17 and $98 \%$ were obtained without and with TM, and the respective kinetic constants were statistically different. In the continuous reactor, discolorations of $7 \%$ and greater than $80 \%$ were reached without and with the addition of TM, respectively, once the reactor entered a steady state.
\end{abstract}




\section{INTRODUCCIÓN}

La contaminación de las aguas superficiales y subterráneas debido a las descargas coloreadas emitidas por las industrias textiles, cosméticas, farmacéuticas, del cuero, del papel y alimenticias generan graves problemas ambientales (Wang et al. 2014), ya a que un $15 \%$ de los colorantes se pierden durante los procesos de producción y aplicación (Wang et al. 2008, Jagruti 2015). Los colorantes azoicos contribuyen con aproximadamente el $70 \%$ de dichos desechos (Matouq et al. 2014) debido a la facilidad de los procesos de obtención, sus elevados coeficientes de extinción molar y su media a alta estabilidad frente a la luz, la humedad y los ataques microbianos (Bafana et al. 2011).

La toxicidad aguda de los colorantes azoicos es relativamente baja, dado que presentan valores de dosis letal para el $50 \%$ de la población ( $\mathrm{DL}_{50}$ ) en el rango de 250-2000 mg/kg de peso corporal (Bafana et al. 2011). Algunos colorantes azoicos (los clasificados como ácidos, básicos y directos) son tóxicos agudos para peces, crustáceos, algas y bacterias, mientras que los colorantes azoicos reactivos poseen valores de concentraciones efectivas muy altas (CE $>100 \mathrm{mg} / \mathrm{L}$ ), por lo que son considerados no tóxicos para los organismos acuáticos (Novotny et al. 2006). La acción carcinogénica y/o mutagénica de los colorantes azo puede deberse a la acción del compuesto como tal, a la formación de arilaminas a través de los procesos reductivos durante las biotransformaciones (Chung et al. 1992, Collier et al. 1993, Rajaguru et al. 1999) o a los productos obtenidos a través de la vía oxidativa del sistema citocromo P450 (Arlt 2002, Umbuzeiro et al. 2005, Wang et al. 2012). Por estas razones, la eliminación del agua de estos compuestos es muy importante para la seguridad del ambiente y la salud humana (Wu et al. 2012).

Las técnicas propuestas para tratar los efluentes que contienen colorantes son numerosas, encontrándose entre ellas la coagulación y la floculación (Sanghi et al. 2007, Fang et al. 2010, Moghaddam et al. 2010), la electrocoagulación (Essadki et al. 2008, Eyvaz et al. 2009), la adsorción sobre diferentes materiales (Crini 2006, Demirbas 2009, Royer et al. 2009, Ahmad y Hameed 2010, Mui et al. 2010), el intercambio iónico (Karcher et al. 2002, Greluk y Hubicki 2013), el tratamiento con ozono (Shu y Huang 1995, Peralta-Zamora et al. 1999, Wu et al. 2008, Tehrani-Bagha et al. 2010), la fotocatálisis (Konstantinou y Albanis 2004, Guettai y Amar 2005, Rauf y Ashraf 2009, Ahmed et al. 2011) y la biodegradación, ya sea mediante hongos (Paszczynski et al. 1992, Robinson y Nigam 2008, Kaushik y Malik
2009, Karthikeyan et al. 2010, Levin et al. 2010), algas (Omar 2008, Lim et al. 2010, Grassi et al. 2011) o bacterias (Khehra et al. 2005, Joshi et al. 2010, Modi et al. 2010, Phugare et al. 2011, Saratale et al. 2011). Los procesos de oxidación avanzados (POA) son métodos fisicoquímicos basados en la producción y utilización de radicales $\mathrm{HO}$ para tratar efluentes, y se ha demostrado que son una herramienta efectiva para aguas coloreadas (Wang 2008, Arslan-Alaton et al. 2009, Mahamuni y Adewuyi 2010, Kalra et al. 2011, Dutta et al. 2015, Guo et al. 2015, Wang et al. 2017).

Entre los POA, el tratamiento mediante ultrasonido se presenta como una metodología atractiva debido a sus ventajas. Los efectos químicos del ultrasonido se deben al fenómeno de cavitación acústica (Adewuyi 2005), el cual involucra la formación, crecimiento y colapso de microburbujas, lo que da lugar a la existencia de "puntos calientes" con condiciones extremas de temperaturas y presiones no alcanzables por métodos tradicionales, superiores a los $5000 \mathrm{~K}$ y 1000 atm (Gogate 2008, Eren e Ince 2010, Eren 2012, Kieffer et al. 2015, Yuan et al. 2016). En estas condiciones extremas se obtiene una gran cantidad de especies reactivas (Pang et al. 2011):

$$
\begin{aligned}
& \left.\left.\left.\mathrm{H}_{2} \mathrm{O}+\right)\right)\right) \rightarrow \mathrm{H} \bullet+\mathrm{HO} \bullet \\
& 2 \mathrm{HO} \bullet \rightarrow \mathrm{H}_{2} \mathrm{O}+\mathrm{O} \bullet \\
& \mathrm{O} \bullet+\mathrm{H}_{2} \mathrm{O} \rightarrow 2 \mathrm{HO} \bullet \\
& \mathrm{O} \bullet+\mathrm{HO} \bullet \rightarrow \mathrm{HOO} \bullet \\
& \mathrm{HOO} \bullet+\mathrm{HO} \bullet \rightarrow \mathrm{H}_{2} \mathrm{O}+\mathrm{O}_{2} \\
& 2 \mathrm{HO} \bullet \rightarrow \mathrm{H}_{2} \mathrm{O}_{2} \\
& 2 \mathrm{HOO} \bullet \rightarrow \mathrm{H}_{2} \mathrm{O}_{2}+\mathrm{O}_{2} \\
& \mathrm{H} \bullet+\mathrm{H}_{2} \mathrm{O}_{2} \rightarrow \mathrm{H}_{2} \mathrm{O}+\mathrm{HO}_{\bullet} \\
& \mathrm{HO} \bullet+\mathrm{H}_{2} \mathrm{O}_{2} \rightarrow \mathrm{HOO}^{\circ}+\mathrm{H}_{2} \mathrm{O} \\
& \mathrm{RH}+\mathrm{HO}_{\bullet} \rightarrow \mathrm{R}_{\bullet}+\mathrm{H}_{2} \mathrm{O} \\
& \mathrm{H} \bullet+\mathrm{HO}_{\bullet} \rightarrow \mathrm{H}_{2} \mathrm{O}
\end{aligned}
$$


Existe una gran cantidad de trabajos (Wang et al. 2007, Bejarano-Pérez y Suárez-Herrera 2008, Okitsu et al. 2008, Ghodbane y Hamdaoui 2009, Guo et al. 2010) donde se reporta el uso de tetracloruro de carbono como agente sinérgico, ya que este compuesto disminuye la recombinación de radicales oxhidrilos (ecuación 11), sustrayendo $\mathrm{H} \bullet \mathrm{y}$ dando lugar a la formación de nuevas especies altamente reactivas:

$$
\begin{aligned}
& \left.\left.\left.\mathrm{CCl}_{4}+\right)\right)\right) \rightarrow \mathrm{CCl}_{3} \bullet+\mathrm{Cl} \bullet \\
& \left.\left.\left.\mathrm{CCl}_{3} \bullet+\right)\right)\right) \rightarrow \mathrm{CCl}_{2} \bullet+\mathrm{Cl} \bullet \\
& \mathrm{Cl}+\mathrm{Cl} \bullet \rightarrow \mathrm{Cl}_{2} \\
& \mathrm{Cl}_{2}+\mathrm{H}_{2} \mathrm{O} \rightarrow \mathrm{HOCl}+\mathrm{HCl} \\
& \mathrm{Cl} \bullet+\mathrm{H}_{2} \mathrm{O} \rightarrow \mathrm{HCl}+\mathrm{HO} \bullet \\
& 2 \mathrm{Cl} \bullet+\mathrm{H}{ }_{2} \mathrm{O} \rightarrow \mathrm{HCl}+\mathrm{HOCl} \\
& \mathrm{CCl}_{4}+\mathrm{H} \bullet \rightarrow \mathrm{HCl}+\mathrm{CCl}_{3} \bullet
\end{aligned}
$$

Para el TM (que también es secuestrante de radicales hidrógenos), además de las ecuaciones 13 a 17, pueden agregarse las siguientes reacciones:

$$
\begin{gathered}
\left.\left.\left.\mathrm{HCCl}_{3}+\right)\right)\right) \rightarrow \mathrm{CHCl}_{2}+\bullet \mathrm{Cl} \\
\mathrm{H} \bullet+\mathrm{HCCl}_{3} \rightarrow \mathrm{HCl}+\bullet \mathrm{CHCl}_{2} \\
\mathrm{H} \bullet+\mathrm{HCCl}_{3} \rightarrow \mathrm{H}_{2}+\bullet \mathrm{CCl}_{3}
\end{gathered}
$$

$\left.\left.\left.\mathrm{HCCl}_{3}+\right)\right)\right) \rightarrow \cdot \mathrm{CCl}_{3}+\cdot \mathrm{H}$

Bhatnagar y Cheung (1994) señalan que la degradación sonoquímica del TM en medio acuoso sigue una cinética de falso primer orden, con un valor de la constante de velocidad de $0.0431 / \mathrm{min}$, siendo el $\mathrm{HCl}$ el único producto detectado.

En este estudio se eligió al anaranjado de metilo (ácido 4-(((4-dimetilamino)fenil)azo)benzeno sulfónico), un colorante azoico utilizado en la industria textil que puede causar irritación al contacto con la piel, los ojos, el sistema respiratorio superior, y que puede ocasionar irritaciones, náusea, vómito y diarrea si es ingerido (TTI 2016). Si bien puede clasificarse como un compuesto moderadamente tóxico en caso de una ingestión única $\mathrm{DL}_{50}=60 \mathrm{mg} / \mathrm{kg}$ (oral, ratas) y $101 \mathrm{mg} / \mathrm{kg}$ (intraperitoneal, ratones) es un colorante considerado mutagénico de acuerdo con ensayos realizados en células humanas (fibroblastos), en células embrionarias en ratones y en células del riñón en hamsters (Sigma-Aldrich 2004). Por estas razones, el AM es muy utilizado como colorante modelo en estudios de degradación de contaminantes (Marci et al. 2003, Zhang et al. 2006, Ali y Abdullah 2011, Haji et al. 2011, Kodom et al. 2012, Urmi et al. 2015, Tang 2013, Hakamada et al. 2014, Zhao et al. 2014, Wang et al. 2015, Zyoud et al. 2015, Youssef et al. 2016, Yuan et al. 2016). Nuestro trabajo también lo hace, planteando como objetivo la posibilidad de utilizar el ultrasonido como tratamiento para aguas coloreadas con AM, analizando el efecto del uso de triclorometano sobre la velocidad de decoloración, y utilizando un reactor por lotes y uno continuo. Se eligió al TM como alternativa al tetracloruro de carbono, por ser el primero más soluble en agua y poseer mayor presión de vapor, lo que favorece su ingreso en las burbujas de cavitación.

Guivarch et al. (2003) propusieron un mecanismo de reacción para la degradación completa del AM (hasta $\mathrm{CO}_{2}$ y $\mathrm{H}_{2} \mathrm{O}$ ), cuyas primeras reacciones se muestran en la ecuación 23. Dado que en nuestro trabajo no se analizaron los compuestos intermedios, no se pudo corroborar si los productos de degradación son los mismos durante la decoloración sonoquímica.

$$
\begin{aligned}
\mathrm{Am} & \underset{\mathrm{HO} \cdot+\mathrm{O}_{2}}{\longrightarrow} \mathrm{NO}_{2} \mathrm{Ph} \underset{\mathrm{HO} \cdot+\mathrm{O}_{2}}{\longrightarrow} \\
\mathrm{NO}_{2} \mathrm{Ph} \mathrm{OH} & \underset{\mathrm{HO} \cdot-\mathrm{NO}_{2}}{\longrightarrow} \mathrm{HO} \mathrm{Ph} \mathrm{OH}
\end{aligned}
$$

donde $\mathrm{NO}_{2} \mathrm{Ph}=$ nitrobenceno, $\mathrm{NO}_{2} \mathrm{PhOH}=\mathrm{p}$ nitrofenol y $\mathrm{HO} \mathrm{Ph} \mathrm{OH}=1,4$ - dihidroxibenceno.

\section{MATERIALES Y MÉTODOS}

\section{Reactivos y equipos analíticos}

Se utilizó AM grado analítico Mallinckrodt (PM: 327.34 g/mol, CAS: 547-58-0) y triclorometano proanálisis Cicarelli (PM: $119.38 \mathrm{~g} / \mathrm{mol}$, densidad $1.49 \mathrm{~g} / \mathrm{mL}$, CAS: 67-66-3). Para preparar las soluciones se utilizó agua ultrapura (osmosis inversa, desionizada) de conductividad $<0.05 \mathrm{mS} / \mathrm{cm}$. Las concentraciones de AM se midieron por espectrometría visible en un equipo HATCH DR/2010 a $465 \mathrm{~nm}$ (Cheng et al. 2012). Las determinaciones de $\mathrm{pH}$ se efectuaron con un equipo HATCH Sension PH1. Todos los ensayos de decoloración (tanto en el reactor por lotes como en el continuo) se hicieron por triplicado. 
En el reactor por lotes el valor medio de la concentración inicial de las soluciones de AM fue de 3.45 $\mathrm{mg} / \mathrm{L} \pm 0.04 \mathrm{mg} / \mathrm{L}$ para los ensayos sin agregado de $\mathrm{TM}$, mientras que para los ensayos con TM fueron de $3.88 \mathrm{mg} / \mathrm{L} \pm 0.02 \mathrm{mg} / \mathrm{L}$. En ambos casos el valor del $\mathrm{pH}$ inicial fue de 5.7. Las concentraciones iniciales de AM y los valores de caudales utilizados en el reactor continuo se muestran en el cuadro I.

CUADRO I. PROMEDIOS Y DESVIACIONES ESTÁNDAR DE LAS CONCENTRACIONES Y CAUDALES UTILIZADOS EN EL REACTOR CONTINUO

\begin{tabular}{lcc}
\hline & $\begin{array}{c}\text { Concentraciones } \\
\text { (promedio/desviación } \\
\text { estándar) }(\mathrm{mg} / \mathrm{L})\end{array}$ & $\begin{array}{c}\text { Caudales (promedio/ } \\
\text { desviación estándar) } \\
\text { (L/h) }\end{array}$ \\
\hline & $3.55 / 0.11$ & $9.8 / 0.3$ \\
$\mathrm{Con} 1 \mathrm{~mL}$ de & $5.10 / 0.10$ & $9.5 / 0.2$ \\
$\mathrm{HCCl} / \mathrm{L}$ & $6.95 / 0.20$ & $9.2 / 0.3$ \\
& $8.96 / 0.37$ & $10.2 / 0.5$ \\
\hline $\mathrm{Sin} \mathrm{HCCl}_{3}$ & $1.97 / 0.10$ & $9.7 / 0.1$ \\
\hline
\end{tabular}

\section{Equipos de ultrasonido}

El reactor sonoquímico por lotes es un equipo MSE provisto de un cabezal de $13 \mathrm{~mm}$ de diámetro, que opera a una frecuencia de $20 \mathrm{kHz}$ sumergido 2 $\mathrm{cm}$ en el líquido. La potencia entregada por el equipo fue determinada mediante calorimetría (Thompson y Doraiswamy 1999) en experiencias efectuadas por triplicado, que dieron como resultado una potencia efectiva de $35.3 \mathrm{~W} \pm 0.58 \mathrm{~W}$. Se utilizó un reactor de vidrio con capacidad de $250 \mathrm{~mL}$, con camisa de refrigeración, por la que se hizo circular agua para regular la temperatura de operación a $25 \pm 1^{\circ} \mathrm{C}$.

El reactor continuo (construido por el Grupo de Química Ambiental, Fig. 1) está compuesto por cuatro unidades: la primera de $0.530 \mathrm{~L}(20 \mathrm{kHz}$ y $33.6 \mathrm{~W} \pm 0.79 \mathrm{~W}$ ), la segunda de $0.526 \mathrm{~L}$ ( $40 \mathrm{KHzy}$ $17 \mathrm{~W} \pm 0.75 \mathrm{~W})$, la tercera de $0.529 \mathrm{~L}(20 \mathrm{kHz}$ y $27.0 \mathrm{~W} \pm 0.42 \mathrm{~W}$ ) y la cuarta de $0.535 \mathrm{~L}(40 \mathrm{kHz}$ y $49.7 \mathrm{~W} \pm 0.23 \mathrm{~W}$ ). Las cuatro unidades conforman un solo cuerpo y cada una descarga en la siguiente a través de un rebosadero. La alimentación del agua a tratar se efectúa mediante una bomba peristáltica. Cada unidad tiene un sistema de ventilación forzada para mantener temperaturas estables (en estos ensayos las mismas variaron entre 24 y $28^{\circ} \mathrm{C}$ ).

\section{Programas utilizados}

Los datos se analizaron mediante la hoja de cálculo Gnumeric (2014). Se realizó un modelo del funcionamiento del reactor continuo mediante el

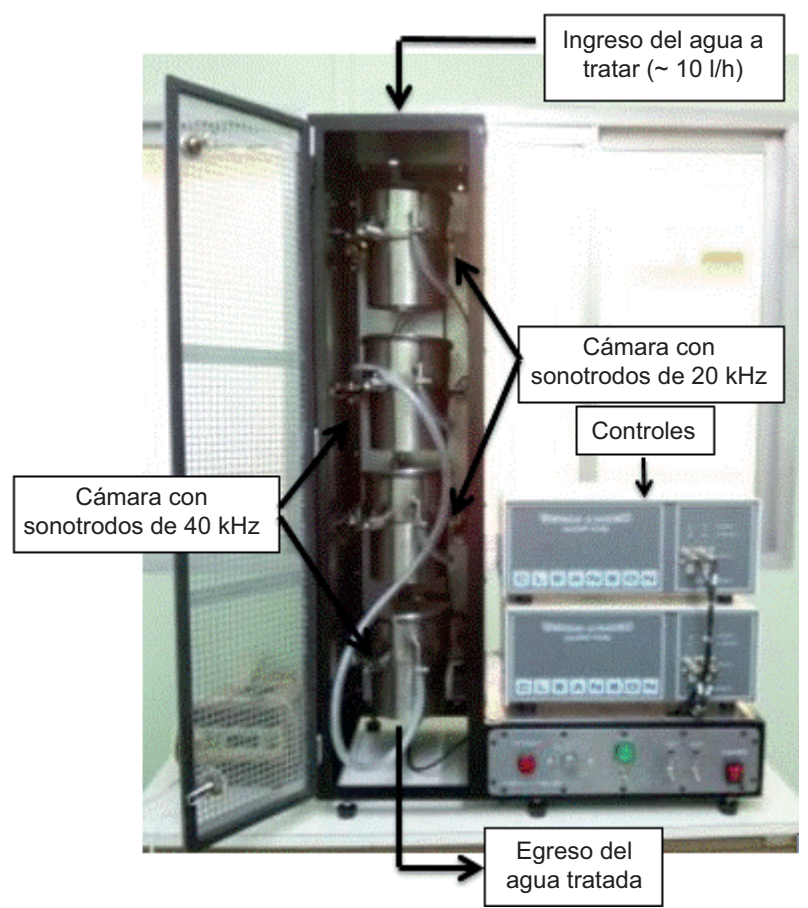

Fig. 1. Equipo de ultrasonido continuo

lenguaje simbólico XCOS (Scilab 2017) con el fin de verificar el tiempo de residencia, utilizando para cada una de las unidades el balance de masas indicado en la siguiente ecuación:

Q. $C_{i-1}=V_{i} \frac{d C_{i}}{d t}+Q \cdot C_{i}+K_{i} \cdot V_{i} \cdot C_{i}$

donde $Q=$ caudal, $i=$ número de la unidad $(i=1-4)$, $C_{\mathrm{i}}=$ concentración en la unidad $i\left(C_{0}=\right.$ concentración de ingreso), $V_{\mathrm{i}}=$ volumen de la unidad $i$ y $K_{\mathrm{i}}=$ constante cinética de primer orden.

\section{RESULTADOS}

\section{Reactor por lotes}

AM sin agregado de $\mathrm{HCCl}_{3}$

En la figura 2 se muestra la evolución de las concentraciones (expresadas en porcentajes de la concentración inicial) en función del tiempo, así como las variaciones de $\mathrm{pH}$. Las barras verticales indican el rango entre los valores máximo y mínimo, mientras que los círculos el valor medio de las tres medidas. Para el caso del $\mathrm{pH}$ se grafican únicamente los valores medios. Se muestran además las ecuaciones de ajuste (de seudoprimer orden en el caso del AM y polinómica de segundo orden para el $\mathrm{pH}$ ) con los respectivos coeficientes de determinación. 


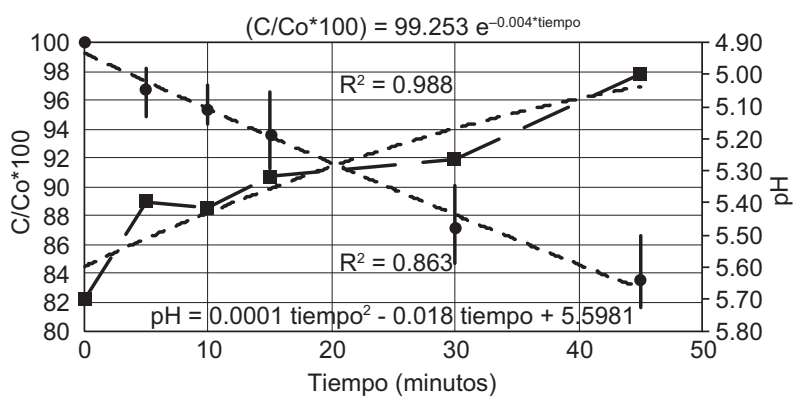

Fig. 2. Decoloración del anaranjado de metilo (AM) $\sin \mathrm{HCCl}_{3}$ en el reactor por lotes (círculos: AM; cuadrados: $\mathrm{pH}$ )

\section{AM con agregado de $\mathrm{HCCl}_{3}$}

En la figura 3 se presentan los resultados de los ensayos realizados con el agregado de tres concentraciones diferentes de cloroformo $(1,2$ y $3 \mathrm{~mL} / \mathrm{L})$ (se grafican únicamente los valores medios). En el cuadro II se muestran los valores de las constantes cinéticas de decoloración de primer orden y de seudoprimer orden ajustadas a los datos mostrados en la figura 3, junto con los respectivos coeficientes de determinación, que en todos los casos son estadísticamente significativos. Los resultados indican un hecho ya observado por otros autores para el $\mathrm{CCl}_{4}$ (Bejarano-Pérez y Suárez-Herrera
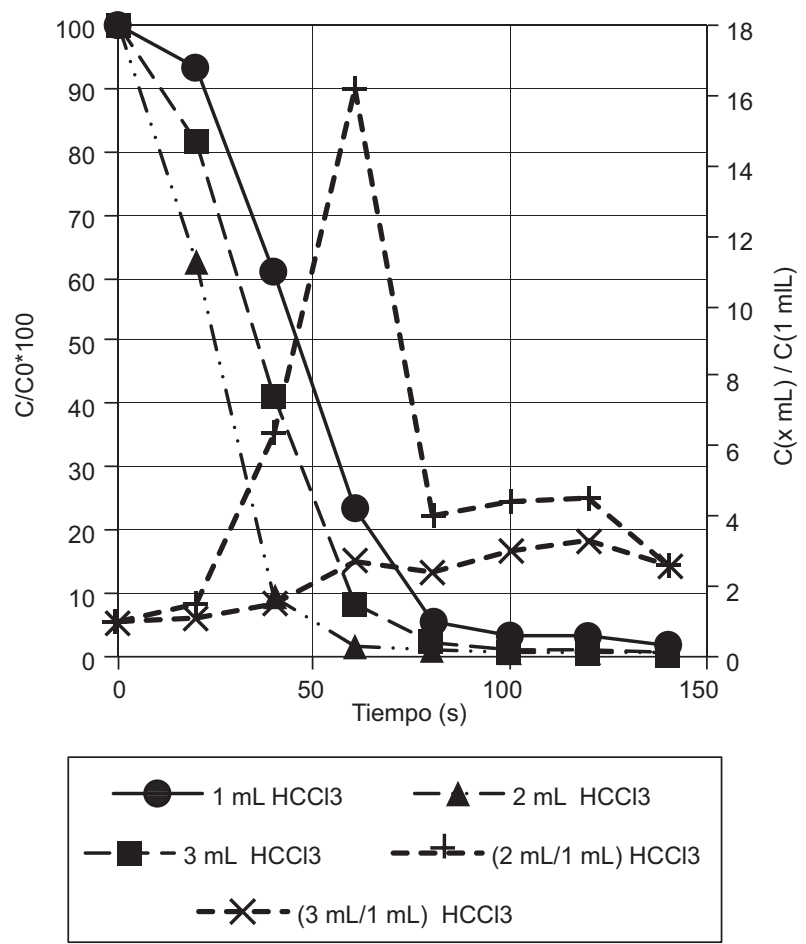

Fig. 3. Decoloración del anaranjado de metilo con diferentes concentraciones de $\mathrm{HCCl}_{3}$ en el reactor por lotes
2008, Chakinala et al. 2008, Guo et al. 2010): que la velocidad aumenta a medida que se incrementa la concentración de $\mathrm{HCCl}_{3}$ hasta un máximo a partir del cual comienza a decaer lentamente. En nuestro caso, dicho máximo se presentó para el agregado de $2 \mathrm{~mL} / \mathrm{L}$.

CUADRO II. CONSTANTES DE VELOCIDAD DE DECOLORACIÓN DEL ANARANJADO DE METILO DE PRIMER $\left(\mathrm{k}_{1}\right)$ Y SEUDOPRIMER ORDEN $\left(\mathrm{k}_{\mathrm{S} 1}\right)$ Y COEFICIENTES DE DETERMINACIÓN $\left(\mathrm{R}^{2}\right)$

\begin{tabular}{lccc}
\hline $\begin{array}{l}\mathrm{mL} \mathrm{HCCl} / \mathrm{L} \\
\text { solución }\end{array}$ & 1 & 2 & 3 \\
\hline $\mathrm{k}_{1}(1 / \mathrm{s}) / \mathrm{R}^{2}$ & $0.0295 / 0.9314$ & $0.0443 / 0.8211$ & $0.0392 / 0.9401$ \\
$\mathrm{k}_{\mathrm{s} 1}(1 / \mathrm{s}) / \mathrm{R}^{2}$ & $0.0328 / 0.9449$ & $0.0414 / 0.8405$ & $0.0412 / 0.9433$ \\
\hline
\end{tabular}

\section{Comparación de resultados}

Con el fin de analizar el efecto sinérgico (ES) Madhavan et al. (2010) y Cheng et al. (2012) propusieron utilizar relaciones entre las constantes de velocidad. En nuestro caso éstas quedan expresadas en la siguiente ecuación:

$E S=\frac{k_{1}\left(\text { con } \mathrm{HCCl}_{3}+\text { ultrasonido }\right)}{\left.k_{1}\left(\text { con } \mathrm{HCCl}_{3} \sin \text { ultrasonido }\right)+k_{1} \text { (ultrasonido } \sin \mathrm{HCCl}_{3}\right)}$

Utilizando los datos del cuadro II (el valor de la constante cinética de primer orden igual a 0.00421 / min para la decoloración sin triclorometano y la no decoloración del $\mathrm{AM}$ con $\mathrm{HCCl}_{3}$ ) se obtienen los datos mostrados en el cuadro III.

CUADRO III. EFECTO SINÉRGICO (ES) DEL AGREGADO DE TRICLOROMETANO EN EL REACTOR POR LOTES

\begin{tabular}{lccc}
\hline $\mathrm{mL} \mathrm{HCCl}_{3} / \mathrm{L}$ solución & 1 & 2 & 3 \\
\hline $\mathrm{ES}$ & 421.4 & 632.9 & 560.0 \\
\hline
\end{tabular}

Para verificar estadísticamente el efecto sinérgico se compararon las constantes de primer orden sin TM y la correspondiente al agregado de $1 \mathrm{~mL} / \mathrm{L}$ de TM (con la cual se observa el menor porcentaje de decoloración). En el cuadro IV se presentan los datos del cálculo de la homocedasticidad utilizando el estadístico F de Snedecor, así como los correspondientes a la prueba $t$ de Student para varianzas inhomogéneas. Los resultados muestran que ambas constantes son estadísticamente diferentes (con un nivel de confianza del $95 \%$ ). 
CUADRO IV. ANÁLISIS DE LA HOMOCEDASTICIDAD DE LAS VARIANZAS Y DE LAS DIFERENCIAS ENTRE LAS CONSTANTES DE DECOLORACIÓN

\begin{tabular}{|c|c|c|}
\hline & $\begin{array}{c}\text { Sin el } \\
\text { agregado } \\
\text { de TM }\end{array}$ & $\begin{array}{c}\text { Con el } \\
\text { agregado de } \\
\text { TM }\end{array}$ \\
\hline Constante de primer orden & $3.9910^{-3}(1 / \mathrm{min})$ & $1.740(1 / \mathrm{min})$ \\
\hline Varianza de la constante & $4.66710^{-8}$ & $2.14110^{-2}$ \\
\hline Grados de libertad & 5 & 9 \\
\hline F calculado & \multicolumn{2}{|c|}{$5.5910^{5}$} \\
\hline F tabulado (95\%) & \multicolumn{2}{|c|}{4.772} \\
\hline t calculado & \multicolumn{2}{|c|}{11.863} \\
\hline t tabulado (95\%) & \multicolumn{2}{|c|}{2.262} \\
\hline
\end{tabular}

TM: triclorometano, F: estadístico de Snedecor, t: estadístico de Student

\section{Reactor continuo}

En la figura 4 se muestra el porcentaje de decoloración del AM para una concentración baja sin el agregado de cloroformo y para otras cuatro concentraciones mayores con el agregado de $1 \mathrm{~mL} / \mathrm{L}$ de TM.

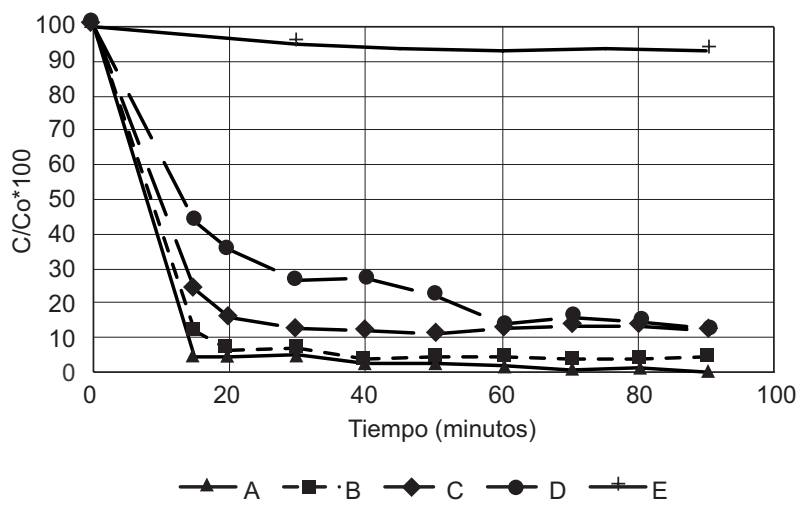

Fig. 4. Decoloración del anaranjado de metilo en reactor continuo. $\mathrm{A}=3.55 \mathrm{mg} / \mathrm{L}, \mathrm{B}=5.10 \mathrm{mg} / \mathrm{L}, \mathrm{C}=6.85 \mathrm{mg} / \mathrm{L}, \mathrm{D}$ $=8.96 \mathrm{mg} / \mathrm{L}, \mathrm{E}=1.97 \mathrm{mg} / \mathrm{L} . \mathrm{A}-\mathrm{D}$ : con el agregado de 1 $\mathrm{mL} / \mathrm{L}$ de $\mathrm{HCCl}_{3} ; \mathrm{E}=$ sin el agregado de $\mathrm{HCCl}_{3}$

Se observa que cuando el equipo entra en estado estacionario sin el agregado de $\mathrm{HCCl}_{3}$, se obtiene un porcentaje de decoloración inferior al $10 \%$, mientras que con el agregado (para las cuatro concentraciones analizadas) se obtiene un porcentaje superior al $80 \%$.

Para calcular el efecto sinérgico se consideraron los porcentajes de decoloración (Pd) en estado estacionario, con corrección por las concentraciones de $\mathrm{AM}\left(\mathrm{C}_{\mathrm{AM}}\right)$ (dado que las utilizadas en los ensayos sin y con cloroformo fueron diferentes), es decir:

$$
E S=\frac{C_{A M}^{C o n} \mathrm{HCCl}_{3} * \mathrm{Pd}^{\mathrm{Con} H C C \mathrm{H}_{3}}}{C_{A M}^{\sin H C C l_{3}} * \mathrm{Pd}^{\mathrm{sin} H C C l_{3}}}
$$

Los resultados obtenidos mediante la aplicación de la ecuación 26 se muestran en el cuadro $\mathbf{V}$. No son comparables con los obtenidos en el reactor por lotes debido a la diferencia en las ecuaciones de cálculo.

\begin{tabular}{lllll} 
CUADRO V. & $\begin{array}{l}\text { EFECTO SINÉRGICO (ES) DEL AGREGADO } \\
\text { DE TRICLOROMETANO EN EL REACTOR } \\
\text { CONTINUO }\end{array}$ \\
\hline $\mathrm{C}_{\mathrm{AM}}(\mathrm{g} / \mathrm{L})$ & 3.55 & 5.04 & 6.95 & 8.69 \\
\hline $\mathrm{ES}$ & 32.6 & 44.4 & 56.4 & 68.1 \\
\hline
\end{tabular}

\section{Simulación dinámica}

Utilizando el editor gráfico XCOS se realizó un modelo de simulación dinámica del reactor continuo. Éste se presenta en la figura $5 \mathbf{a}, \mathbf{b}$, donde se muestran, respectivamente, las cuatro unidades con sus ingresos y egresos, así como un detalle de la primera unidad (los paneles restantes son similares).
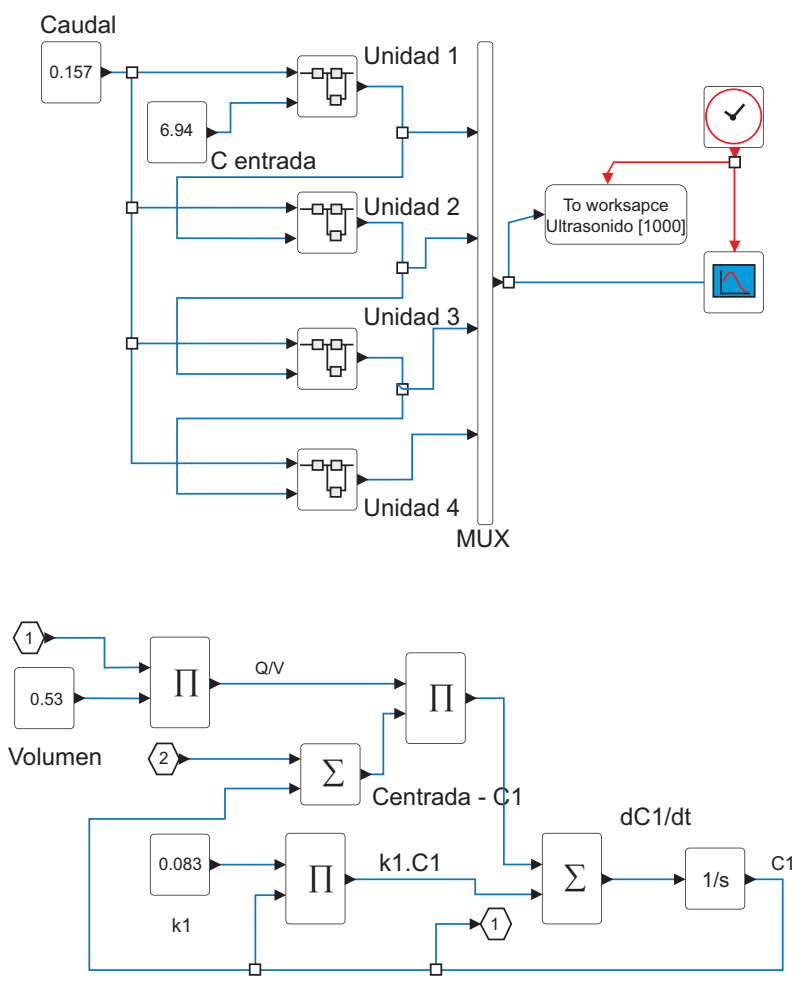

Fig. 5. Superior: diagrama de bloques del reactor continuo. Inferior: detalle del diagrama de bloques correspondiente a la unidad 
En la figura 6 se muestra la salida de la simulación dinámica para cada una de las cuatro unidades del equipo continuo, utilizando como concentración de entrada $6.94 \mathrm{mg} / \mathrm{L}$ de AM y un caudal de $9.4 \mathrm{~L} / \mathrm{h}$ (correspondiente a uno de los ensayos realizados), así como el agregado de $1 \mathrm{~mL} / \mathrm{L}$ de $\mathrm{HCCl}_{3}$.

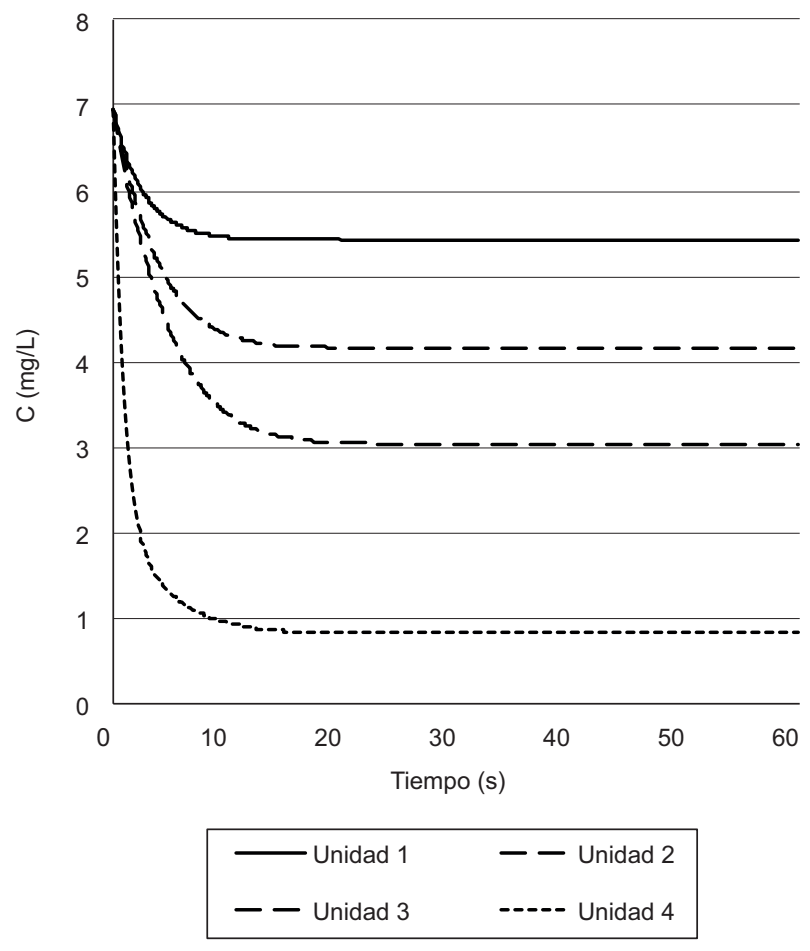

Fig. 6. Salida de la simulación dinámica

\section{DISCUSION}

Se demostró que la decoloración sonoquímica de AM es ampliamente favorecida por la adición de bajas concentraciones de $\mathrm{HCCl}_{3}$. En el caso del reactor por lotes se obtuvieron degradaciones del 17 y el $90 \%$ sin y con este agregado. Este aumento en la velocidad puede explicarse por el hecho de que el cloroformo es más volátil que el agua (presiones de vapor: $p v_{\text {agua }}\left(27^{\circ} \mathrm{C}\right)=26.74$ Torr; $p v_{\text {cloroformo }}\left(30^{\circ} \mathrm{C}\right)$ $=160$ Torr) lo que favorece su ingreso en las burbujas de cavitación; al colapsar éstas dan lugar a las reacciones expresadas en las ecuaciones 19-21, secuestrando radicales $\mathrm{H} \bullet$, lo cual permite un mayor tiempo de vida medio de los radicales $\mathrm{HO} \bullet \mathrm{y}$, por ende, mayor probabilidad de reaccionar. También puede ocurrir la reacción expresada en la ecuación 22, pero debido a que los enlaces $\mathrm{C}-\mathrm{H}$ tienen mayor fuerza que los enlaces $\mathrm{C}-\mathrm{Cl}$, se produce en menor extensión. Para las tres concentraciones de $\mathrm{HCCl}_{3}$ empleadas el efecto sinérgico es superior al $400 \%$.
En el cuadro VI se presenta una recopilación de métodos utilizados para la degradación de AM en reactores por lotes, incluyendo los datos de este trabajo. Más allá de las diferencias observadas en los valores de frecuencias y potencias de los tratamientos utilizando únicamente ultrasonido, en un solo trabajo se obtiene una degradación del $52 \%$, mientras que en los restantes nueve casos (incluido el nuestro), los porcentajes de degradación son inferiores al $20 \%$ : Esto muestra que el método es inadecuado para este fin.

En los 14 artículos revisados en los que se utilizó ultrasonido combinado con otro proceso, los porcentajes de degradación tuvieron un rango muy amplio, desde el $13 \%$ hasta el $98 \%$ obtenido en nuestro caso. La diferencia más notoria se presenta en los tiempos necesarios para alcanzar dichos porcentajes: en nuestro caso el mismo fue de 80 segundos, mientras que en nueve de los restantes fueron iguales o superiores a los 90 minutos (en los otros cuatro no se menciona este dato). Analizando todas las referencias en las cuales se refieren los tiempos de reacción, nuestro tiempo (80 segundos) es el menor, independientemente del proceso utilizado. Observando las constantes de decoloración puede constatarse, además, que de los 43 valores citados cinco corresponden a una cinética de segundo orden y el resto a cinéticas de primer o seudoprimer orden, donde el valor ajustado en nuestro trabajo (1.74 1/min) es el mayor.

Utilizando TM en el reactor continuo se logra una mejora en la decoloración superior al $80 \%$ una vez que el reactor entra en estado estacionario. Mediante la simulación dinámica se encontró que los valores de las concentraciones de cada unidad coinciden con las determinadas en el ensayo cuando el reactor se encuentra en estado estacionario, pero dicho estado se alcanza en un tiempo menor al real. Esto significa que mientras el tiempo de residencia ideal es de $3.2 \mathrm{~min}$, el real es mayor (cercano al doble de dicho valor).

\section{CONCLUSIONES}

Se demostró que el cloroformo puede utlizarse eficazmente como sinergizante en la decoloración sonoquímica del anaranjado de metilo, lo cual se verificó utilizando un reactor por lotes y uno continuo. En el primero se observó un aumento estadísticamente significativo en la constante de velocidad de primer orden superior a 400 veces respecto a la decoloración sin el agregado de TM. Para el caso del reactor continuo la capacidad de decoloración aumentó en más de 30 veces con el agregado de cloroformo. 
CUADRO VI. DEGRADACIÓN DEL ANARANJADO DE METILO (AM) EN REACTORES POR LOTES MEDIANTE DIFERENTES PROCESOS

\begin{tabular}{|c|c|c|c|c|c|}
\hline $\begin{array}{l}\text { Concentración } \\
\text { inicial AM }\end{array}$ & Proceso & $\begin{array}{c}\text { Degradación } \\
(\%)\end{array}$ & Tiempo & $\begin{array}{l}\text { Constante de } \\
\text { degradación }\end{array}$ & Referencia \\
\hline \multirow{3}{*}{$100 \mathrm{mg} / \mathrm{L}$} & US $(40 \mathrm{kHz}-400 \mathrm{~W})$ & 0 & \multirow{3}{*}{$120 \mathrm{~min}$} & \multirow{3}{*}{---} & \multirow{3}{*}{$\begin{array}{l}\text { Chen et al. } \\
2008\end{array}$} \\
\hline & Fenton & 80 & & & \\
\hline & US $(40 \mathrm{kHz}-400 \mathrm{~W})+$ Fenton & 86 & & & \\
\hline $10 \mathrm{ppm}$ & $\mathrm{UV}+\mathrm{ZnO}$ & 100 & \multirow{2}{*}{$60 \mathrm{~min}$} & \multirow{2}{*}{---} & \multirow{2}{*}{$\begin{array}{l}\text { Zyoud et al. } \\
2015\end{array}$} \\
\hline $40 \mathrm{ppm}$ & $\mathrm{UV}+\mathrm{ZnO}$ & 40 & & & \\
\hline \multirow{5}{*}{--- } & US (400 W) & 5 & \multirow{5}{*}{$90 \mathrm{~min}$} & --- & \multirow{5}{*}{$\begin{array}{l}\text { Cheng et al. } \\
2012\end{array}$} \\
\hline & $\mathrm{TiO}_{2}(2 \mathrm{~g} / \mathrm{L})$ & 8 & & --- & \\
\hline & $\mathrm{US}(400 \mathrm{~W})+\mathrm{TiO}_{2}(2 \mathrm{~g} / \mathrm{L})$ & 13 & & $0.00251 / \mathrm{min}$ & \\
\hline & $\mathrm{UV}(11 \mathrm{~W})+\mathrm{TiO}_{2}(2 \mathrm{~g} / \mathrm{L})$ & 66 & & $0.01251 / \mathrm{min}$ & \\
\hline & $\mathrm{US}(400 \mathrm{~W})+\mathrm{UV}(11 \mathrm{~W})+\mathrm{TiO}_{2}(2 \mathrm{~g} / \mathrm{L})$ & 93 & & $0.03101 / \mathrm{min}$ & \\
\hline \multirow{6}{*}{$25 \mathrm{mg} / 1$} & US $(28 \mathrm{kHz}-400 \mathrm{~W})-\mathrm{pH}: 7$ & 15 & \multirow{6}{*}{$100 \mathrm{~min}$} & $0.001551 / \mathrm{min}$ & \multirow{6}{*}{ - Cui et al. 2011} \\
\hline & $\mathrm{TiO}_{2}(0.5 \mathrm{~g} / \mathrm{L})+\mathrm{UV}(30 \mathrm{~W})-\mathrm{pH}: 7$ & 28 & & $0.003231 / \mathrm{min}$ & \\
\hline & $\mathrm{US}(28 \mathrm{kHz}-400 \mathrm{~W})+\mathrm{UV}(30 \mathrm{~W})+\mathrm{TiO}_{2}(2 \mathrm{~g} / \mathrm{L})-\mathrm{pH}: 7$ & 33 & & $0.003881 / \mathrm{min}$ & \\
\hline & US $(28 \mathrm{kHz}-400 \mathrm{~W})-\mathrm{pH}: 4$ & 15 & & $0.001551 / \mathrm{min}$ & \\
\hline & $\mathrm{TiO}_{2}(0.5 \mathrm{~g} / \mathrm{L})+\mathrm{UV}(30 \mathrm{~W})-\mathrm{pH}: 4$ & 41 & & $0.005001 / \mathrm{min}$ & \\
\hline & $\mathrm{US}(28 \mathrm{kHz}-400 \mathrm{~W})+\mathrm{UV}(30 \mathrm{~W})+\mathrm{TiO}_{2}(2 \mathrm{~g} / \mathrm{L})-\mathrm{pH}: 4$ & 62 & & $0.009381 / \mathrm{min}$ & \\
\hline \multirow{6}{*}{$10 \mathrm{ppm}$} & $\mathrm{Fe}^{0}(10 \mathrm{mg})+$ oscuridad & 23 & \multirow{6}{*}{$16 \mathrm{~min}$} & $0.0051 / \mathrm{min}$ & \multirow{6}{*}{$\begin{array}{l}\text { Gomathi-Dev } \\
\text { et al. } 2009\end{array}$} \\
\hline & $\mathrm{Fe}^{0}(10 \mathrm{mg})+\mathrm{PSA}(40 \mathrm{ppm})+$ oscuridad & 47 & & $0.01361 / \mathrm{min}$ & \\
\hline & $\mathrm{Fe}^{0}(10 \mathrm{mg})+\mathrm{H}_{2} \mathrm{O}_{2}(10 \mathrm{ppm})+$ oscuridad & 75 & & $0.0251 / \mathrm{min}$ & \\
\hline & $\mathrm{Fe}^{0}(10 \mathrm{mg})+\mathrm{UV}(125 \mathrm{~W})$ & 61 & & $0.01771 / \mathrm{min}$ & \\
\hline & $\mathrm{Fe}^{0}(10 \mathrm{mg})+\mathrm{PSA}(40 \mathrm{ppm})+\mathrm{UV}(125 \mathrm{~W})$ & 71 & & $0.02971 / \mathrm{min}$ & \\
\hline & $\mathrm{Fe}^{0}(10 \mathrm{mg})+\mathrm{H}_{2} \mathrm{O}_{2}(10 \mathrm{ppm})+\mathrm{UV}(125 \mathrm{~W})$ & 100 & & $0.10251 / \mathrm{min}$ & \\
\hline $20 \mathrm{mg} / \mathrm{L}$ & $\mathrm{UV}+\mathrm{TiO}_{2}(0.5 \mathrm{~g} / \mathrm{L})$ & \multirow{2}{*}{100} & $75 \min$ & --- & \multirow{2}{*}{$\begin{array}{l}\text { Hernández et } \\
\text { al. } 2012\end{array}$} \\
\hline $80 \mathrm{mg} / \mathrm{L}$ & $\mathrm{UV}+\mathrm{TiO}_{2}(0.5 \mathrm{~g} / \mathrm{L})$ & & $420 \mathrm{~min}$ & --- & \\
\hline \multirow{4}{*}{$100 \mathrm{mmol} / \mathrm{L}$} & US $(20 \mathrm{kHz}-40 \mathrm{~W})$ & 4 & \multirow{4}{*}{$120 \mathrm{~min}$} & \multirow{4}{*}{---} & \multirow{4}{*}{$\begin{array}{l}\text { Paniwnyk et } \\
\text { al. } 2010\end{array}$} \\
\hline & $\mathrm{US}(40 \mathrm{kHz}-40 \mathrm{~W})$ & 1 & & & \\
\hline & $\mathrm{US}(512 \mathrm{kHz}-40 \mathrm{~W})$ & 19 & & & \\
\hline & $\mathrm{US}(850 \mathrm{kHz}-40 \mathrm{~W})$ & 52 & & & \\
\hline \multirow{3}{*}{$10 \mathrm{mg} / \mathrm{L}$} & US $(40 \mathrm{kHz}-50 \mathrm{~W})$ & 16 & \multirow{3}{*}{$150 \mathrm{~min}$} & \multirow{3}{*}{---} & \multirow{3}{*}{$\begin{array}{l}\text { Wang et al. } \\
2005\end{array}$} \\
\hline & US $(40 \mathrm{kHz}-50 \mathrm{~W})+\mathrm{TiO}_{2}(0.5 \mathrm{~g} / \mathrm{L})$ anatase & 42 & & & \\
\hline & US $(40 \mathrm{kHz}-50 \mathrm{~W})+\mathrm{TiO}_{2}(0.5 \mathrm{~g} / \mathrm{L})$ rutilo & 97 & & & \\
\hline & MI $(2450 \mathrm{MHz}-500 \mathrm{~W})$ & 2 & & & \\
\hline $100 \mathrm{mg} / \mathrm{L}$ & Fenton & 50 & $8 \mathrm{~min}$ & --- & Wang et al. \\
\hline & MI $(2450 \mathrm{MHz}-500 \mathrm{~W})+$ Fenton & 100 & & & \\
\hline $5.410^{-5} \mathrm{~mol} / \mathrm{L}$ & Fenton & --- & --- & $\begin{array}{c}4.9310^{4} \\
1 /(\mathrm{M} . \mathrm{min})\end{array}$ & $\begin{array}{l}\text { Youssef et al. } \\
2016\end{array}$ \\
\hline $20 \mathrm{mo} / \mathrm{I}$ & $\mathrm{TiO}_{2} \mathrm{SGE}+$ oscuridad & 42 & & & \\
\hline $20 \mathrm{mg} / \mathrm{L}$ & $\mathrm{TiO}_{2} \mathrm{SGE}+\mathrm{UV}$ & 50 & & $\cdots-$ & \\
\hline & $\mathrm{TiO}_{2} \mathrm{SGE}+\mathrm{UV}\left(15^{\circ} \mathrm{C}\right)$ & 29 & & $\begin{array}{c}0.00030 \\
1 /(\% . \min )\end{array}$ & Pang y Song \\
\hline $50 \mathrm{mg} / \mathrm{L}$ & $\mathrm{TiO}_{2} \mathrm{SGE}+\mathrm{UV}\left(25^{\circ} \mathrm{C}\right)$ & 24 & $12 \mathrm{n}$ & $\begin{array}{c}0.00098 \\
1 /(\% . \min )\end{array}$ & 2012 \\
\hline & $\mathrm{TiO}_{2} \mathrm{SGE}+\mathrm{UV}\left(35^{\circ} \mathrm{C}\right)$ & 20 & & $\begin{array}{c}0.00250 \\
1 /(\% . \min )\end{array}$ & \\
\hline
\end{tabular}

US: ultrasonido, UV: ultravioleta, PSA: persulfato de amonio, MI: microondas, SGE: soportado sobre grafito expandido, SPE: soportado sobre perileno, LS: luz solar, LSS: luz solar simulada, HPA: ácido fosfotúngstico, CH: cavitación hidrodinámica, SAI: soportado sobre acero inoxidable 
CUADRO VI. DEGRADACIÓN DEL ANARANJADO DE METILO (AM) EN REACTORES POR LOTES MEDIANTE DIFERENTES PROCESOS

\begin{tabular}{|c|c|c|c|c|c|}
\hline $\begin{array}{l}\text { Concentración } \\
\text { inicial AM }\end{array}$ & Proceso & $\begin{array}{c}\text { Degradación } \\
(\%)\end{array}$ & Tiempo & $\begin{array}{l}\text { Constante de } \\
\text { degradación }\end{array}$ & Referencia \\
\hline \multirow{6}{*}{$0.01 \mathrm{mM}$} & $\mathrm{TiO}_{2} \mathrm{SPE}+$ oscuridad & 0 & \multirow{6}{*}{$6 \mathrm{~h}$} & \multirow{6}{*}{---} & \multirow{6}{*}{$\begin{array}{l}\text { Zhiyong et al. } \\
2008\end{array}$} \\
\hline & $\mathrm{LSS}\left(90 \mathrm{~mW} / \mathrm{cm}^{2}\right)+\mathrm{PE}$ & 8 & & & \\
\hline & $\mathrm{TiO}_{2} \mathrm{SPE}+\mathrm{LSS}\left(90 \mathrm{~mW} / \mathrm{cm}^{2}\right)$ & 100 & & & \\
\hline & $\mathrm{TiO}_{2} \mathrm{SPE}+\mathrm{LSS}\left(60 \mathrm{~mW} / \mathrm{cm}^{2}\right)$ & 90 & & & \\
\hline & $\mathrm{LSS}\left(90 \mathrm{~mW} / \mathrm{cm}^{2}\right)+\mathrm{H}_{2} \mathrm{O}_{2}(1 \mathrm{mM})$ & 25 & & & \\
\hline & $\mathrm{LSS}\left(90 \mathrm{~mW} / \mathrm{cm}^{2}\right)+\mathrm{H}_{2} \mathrm{O}_{2}(2 \mathrm{mM})$ & 35 & & & \\
\hline $5 \mathrm{mg} / \mathrm{L}$ & \multirow{3}{*}{$-0.6 \mathrm{~g} / \mathrm{L} \mathrm{HPA}+\mathrm{UV}(254 \mathrm{~nm}-30 \mathrm{~W})$} & 98 & \multirow{3}{*}{$60 \mathrm{~min}$} & $0.04711 / \mathrm{min}$ & \multirow{3}{*}{ Zhong 2013} \\
\hline $10 \mathrm{mg} / \mathrm{L}$ & & 80 & & $0.02711 / \mathrm{min}$ & \\
\hline $20 \mathrm{mg} / \mathrm{L}$ & & 53 & & $0.01501 / \mathrm{min}$ & \\
\hline $0.3 \mathrm{~g} / \mathrm{L}$ & \multirow{2}{*}{-Perreniporia tephropora $\left(30{ }^{\circ} \mathrm{C}\right)$} & 71 & 15 días & \multirow{2}{*}{---} & \multirow{2}{*}{$\begin{array}{l}\text { Mounguengui } \\
\text { et al. } 2014\end{array}$} \\
\hline $0.2 \mathrm{~g} / \mathrm{L}$ & & 100 & 7 días & & \\
\hline--- & Cenizas de cáscara de arroz & 53 & $7 \mathrm{~h}$ & $\begin{array}{c}0.02465 \\
1 /(\mathrm{mM} . \mathrm{min}) \\
\end{array}$ & $\begin{array}{l}\text { Purbaningtias } \\
\text { et al. } 2015\end{array}$ \\
\hline \multirow{6}{*}{$10 \mathrm{mg} / \mathrm{L}$} & $8 \mathrm{mg} / \mathrm{L} \mathrm{Cl}_{2} \mathrm{O}+\mathrm{CH}\left(25^{\circ} \mathrm{C}-0.6 \mathrm{MPa}\right)$ & 22 & \multirow{3}{*}{$40 \mathrm{~min}$} & \multirow{3}{*}{---} & \multirow{3}{*}{$\begin{array}{l}\text { Yang et al. } \\
2017\end{array}$} \\
\hline & $8 \mathrm{mg} / \mathrm{L} \mathrm{Cl}_{2} \mathrm{O}+\mathrm{CH}\left(40^{\circ} \mathrm{C}-0.6 \mathrm{MPa}\right)$ & 38 & & & \\
\hline & $8 \mathrm{mg} / \mathrm{L} \mathrm{Cl}{ }_{2} \mathrm{O}+\mathrm{CH}\left(35^{\circ} \mathrm{C}-0.4 \mathrm{MPa}\right)$ & 71 & & & \\
\hline & $100 \mathrm{mg} \mathrm{Bi}_{2}\left(\mathrm{MoO}_{4}\right)_{3}+\mathrm{LS}+\mathrm{H}_{2} \mathrm{O}_{2}$ & 100 & $70 \mathrm{~min}$ & $6.210^{-4} 1 / \mathrm{min}$ & \multirow{3}{*}{$\begin{array}{l}\text { Suresh et al. } \\
2015\end{array}$} \\
\hline & $100 \mathrm{mg} \mathrm{Bi}_{2}\left(\mathrm{MoO}_{4}\right)_{3}+\mathrm{H}_{2} \mathrm{O}_{2}$ & 35 & $120 \mathrm{~min}$ & $3.310^{-5} 1 / \mathrm{min}$ & \\
\hline & $100 \mathrm{mg} \mathrm{Bi}_{2}\left(\mathrm{MoO}_{4}\right)_{3}+\mathrm{LS}$ & 5 & $60 \mathrm{~min}$ & $3.310^{-5} 1 / \mathrm{min}$ & \\
\hline \multirow{5}{*}{$5 \mathrm{mg} / \mathrm{L}$} & $\mathrm{UV}(12 \mathrm{~W})+150 \mathrm{mg} \mathrm{TiO} 2$ & 85 & \multirow{5}{*}{$210 \mathrm{~min}$} & $0.01071 / \mathrm{min}$ & \multirow{5}{*}{$\begin{array}{l}\text { Koohestani y } \\
\text { Sadrnezhaad } \\
2016\end{array}$} \\
\hline & $\mathrm{UV}(12 \mathrm{~W})+150 \mathrm{mg}\left(\mathrm{TiO}_{2}+5 \% \mathrm{CuO}\right)$ & 86 & & $0.01101 / \mathrm{min}$ & \\
\hline & $\mathrm{UV}(12 \mathrm{~W})+150 \mathrm{mg}\left(\mathrm{TiO}_{2}+10 \% \mathrm{CuO}\right)$ & 90 & & $0.01231 / \mathrm{min}$ & \\
\hline & $\mathrm{UV}(12 \mathrm{~W})+150 \mathrm{mg}\left(\mathrm{TiO}_{2}+15 \% \mathrm{CuO}\right)$ & 74 & & $0.00751 / \mathrm{min}$ & \\
\hline & $\mathrm{UV}(12 \mathrm{~W})+150 \mathrm{mg} \mathrm{CuO}$ & 40 & & $0.00211 / \mathrm{min}$ & \\
\hline \multirow{2}{*}{$\begin{array}{l}25 \mathrm{ppm} \\
100 \mathrm{ppm}\end{array}$} & \multirow{2}{*}{$-\mathrm{TiO}_{2}+\mathrm{UV}$} & 100 & \multirow{2}{*}{---} & \multirow{2}{*}{---} & \multirow{2}{*}{$\begin{array}{l}\text { Kumar y Pan- } \\
\text { dey } 2017\end{array}$} \\
\hline & & 48 & & & \\
\hline & $\mathrm{UV}(365 \mathrm{~nm}-15 \mathrm{~W})$ & 2 & & --- & \\
\hline & $\mathrm{UV}(365 \mathrm{~nm}-15 \mathrm{~W})+\mathrm{TiO}_{2} / \mathrm{SAI}$ & 43 & & $0.003151 / \mathrm{min}$ & \\
\hline $1 \mathrm{mM}$ & $\mathrm{UV}(365 \mathrm{~nm}-15 \mathrm{~W})+\mathrm{TiO}_{2} /$ vidrio $: \mathrm{SnO}_{2}: \mathrm{F}$ & 58 & $170 \mathrm{~min}$ & $0.005081 / \mathrm{min}$ & Kodom et al. \\
\hline & $\mathrm{UV}(365 \mathrm{~nm}-15 \mathrm{~W})+\mathrm{TiO}_{2} / \mathrm{SAI}+\mathrm{H}_{2} \mathrm{O}_{2}(0.02 \mathrm{M})$ & 80 & & & \\
\hline & $\mathrm{UV}(365 \mathrm{~nm}-15 \mathrm{~W})+\mathrm{TiO}_{2} / \mathrm{SAI}+\mathrm{H}_{2} \mathrm{O}_{2}(0.2 \mathrm{M})$ & 92 & & --- & \\
\hline $20 \mathrm{mg} / \mathrm{L}$ & $-0.8 \mathrm{~g} / \mathrm{L} \mathrm{TiO}_{2}(80 \%$ anatase $-20 \%$ rutilo $)+\mathrm{UV}(13.5 \mathrm{~mW} /$ & 100 & $15 \mathrm{~min}$ & $9.31 / \mathrm{h}$ & \\
\hline $120 \mathrm{mg} / \mathrm{L}$ & $\left.\mathrm{cm}^{2}\right)$ & 95 & $6 \mathrm{~h}$ & $0.61 / \mathrm{h}$ & Marci et al. \\
\hline $20 \mathrm{mg} / \mathrm{L}$ & $-08 \mathrm{o} / \mathrm{T}$ TiOn $($ anatase) $+\mathrm{IVV}(125 \mathrm{~mW} / \mathrm{c}$ & & & $2.41 / \mathrm{h}$ & \\
\hline $120 \mathrm{mg} / \mathrm{L}$ & $0.8 \mathrm{~g} / \mathrm{L} 11 \mathrm{U}_{2}($ anatase $)+\mathrm{U}\left(13.5 \mathrm{mw} / \mathrm{cm}^{-}\right)$ & --- & --- & $0.41 / \mathrm{h}$ & \\
\hline & $\underline{\mathrm{US}}(20 \mathrm{kHz}-70 \mathrm{~W})+1 \mathrm{~g} / \mathrm{L} \mathrm{TiO}_{2}(150-280 \mathrm{~nm})$ & 62 & $1 \mathrm{~h}$ & & Ali y Abdullah \\
\hline $1 \mathrm{~g} / \mathrm{L}$ & $\mathrm{US}(20 \mathrm{kHz}-70 \mathrm{~W})+1 \mathrm{~g} / \mathrm{L} \mathrm{TiO}_{2}(90-160 \mathrm{~nm})$ & 82 & In & -- & 2011 \\
\hline & $\mathrm{UV}+1 \mathrm{~g} / \mathrm{L} \mathrm{ZnO} \mathrm{(forma} \mathrm{cilíndrica)}$ & 40 & & & \\
\hline $10 \mathrm{mg} / \mathrm{L}$ & $\mathrm{UV}+1 \mathrm{~g} / \mathrm{L} \mathrm{ZnO} \mathrm{(forma} \mathrm{grano} \mathrm{de} \mathrm{arroz)}$ & 96 & $60 \mathrm{~min}$ & --- & Tang 2013 \\
\hline & $\mathrm{UV}+1 \mathrm{~g} / \mathrm{L} \mathrm{ZnO} \mathrm{(forma} \mathrm{granular)}$ & 99 & & & \\
\hline & $\underline{\mathrm{US}}(87.5 \mathrm{~W})+\mathrm{O}_{3}(68.8 \mathrm{mg} / \mathrm{L})$ & & & $0.241 / \mathrm{min}$ & \\
\hline $400 \mathrm{mg} / \mathrm{L}$ & $\mathrm{US}(175 \mathrm{~W})+\mathrm{O}_{3}(25.4 \mathrm{mg} / \mathrm{L})$ & --- & --- & $0.151 / \mathrm{min}$ & Zhang et al. \\
\hline & $\mathrm{US}(175 \mathrm{~W})+\mathrm{O}_{3}(114.2 \mathrm{mg} / \mathrm{L})$ & & & $0.381 / \mathrm{min}$ & 2006 \\
\hline $135.3 \mathrm{mg} / \mathrm{L}$ & $\mathrm{US}(175 \mathrm{~W})+\mathrm{O}_{3}(70.3 \mathrm{mg} / \mathrm{L})$ & --- & --- & $0.421 / \mathrm{min}$ & \\
\hline $3.45 \mathrm{mg} / \mathrm{L}$ & US $(20 \mathrm{kHz}-35 \mathrm{~W})$ & 17 & $45 \mathrm{~min}$ & $0.0041 / \mathrm{min}$ & \\
\hline $3.88 \mathrm{mg} / \mathrm{L}$ & US $(20 \mathrm{kHz}-35 \mathrm{~W})+\mathrm{TM}(2 \mathrm{~mL} / \mathrm{L})$ & 98 & $80 \mathrm{~s}$ & $1.7401 / \mathrm{min}$ & bajo) \\
\hline
\end{tabular}

US: ultrasonido, UV: ultravioleta, PSA: persulfato de amonio, MI: microondas, SGE: soportado sobre grafito expandido, SPE: soportado sobre perileno, LS: luz solar, LSS: luz solar simulada, HPA: ácido fosfotúngstico, CH: cavitación hidrodinámica, SAI: soportado sobre acero inoxidable 


\section{REFERENCIAS}

Adewuyi Y.G. (2005). Sonochemistry in environmental remediation. 1. Combinative and hybrid sonophotochemical oxidation processes for the treatment of pollutants in water. Environ. Sci. Technol. 39 (10), 3409-3420. DOI: 10.1021/es049138y

Ahmad A.A. y Hameed B.H. (2010). Fixed-bed adsorption of reactive azo dye onto granular activated carbon prepared from waste. J. Hazard. Mater. 175 (1-3), 298303. DOI: 10.1016/j.jhazmat.2009.10.003

Ahmed S., Rasul M.G., Martens W.N. y Hashib M.A. (2011). Advances in heterogeneous photocatalytic degradation of phenols and dyes in wastewater: a review. Water Air Soil Poll. 215 (1-4), 1-39.

DOI: $10.1007 / \mathrm{s} 11270-010-0456-3$

Arslan-Alaton I., Tureli G. y Olmez-Hanci T. (2009). Treatment of azo-dyes production wastewater using Photo-Fenton-like advanced oxidation processes: Optimization by response surface methodology. J. Photoch. Photobio. A 202, 142-153.

DOI: 10.1016/j.jphotochem.2008.11.019

Arlt V.M. (2002). Metabolic activation of the environmental contaminant 3 nitrobenzanthrone by human acetyltransferases and sulfotransferase. Carcinogenesis 23 (11), 1937-1945.

DOI: $10.1093 / \mathrm{carcin} / 23.11 .1937$

Bafana A., Devi S.S. y Chakrabarti T. (2011). Azo dyes: past, present and the future. Environ. Rev. 19, 350-370. DOI: 10.1139/a11-018

Bhatnagar A. y Cheung H.M. 1994. Sonochemical destruction of chlorinated $\mathrm{C} 1$ and $\mathrm{C} 2$ volatile organic compounds in dilute aqueous solution. Environ. Sci. Technol. 28 (8), 1481-1486. DOI: 10.1021/es00057a016

Bejarano-Pérez N.J. y Suárez-Herrera M.F. (2008). Sonochemical and sonophotocatalytic degradation of malachite Green: The effect of carbon tetrachloride on reaction rates. Ultrason. Sonochem. 15, 612-617. DOI: 10.1016/j.ultsonch.2007.09.009

Chakinala A.G., Gogate P.R., Chand R., Bremner D.H., Molina R. y Burgess A.E. (2008). Intensification of oxidation capacity using chloroalkanes as additives in hydrodynamic and acoustic cavitation reactors. Ultrason. Sonochem. 15, 164-170. DOI: 10.1016/j.ultsonch.2007.02.008

Chen C., Cheng J., Pang C. y Zheng Z. (2008). Degradation of azo dyes by hybrid ultrasound - Fenton reagent. Memorias. $2^{\text {nd }}$ International Conference on Bioinformatics and Biomedical Engineering. Shanghai. 16 al 18 de mayo, 2008. pp. 3600-3603.

DOI: $10.1109 /$ ICBBE.2008.402

Cheng Z., Quan X., Xiong Y., Yang L. y Huang Y. (2012). Synergistic degradation of methyl orange in a ultrasound intensified photocatalytic reactor. Ultrason. Sonochem. 19, 1027-1032.

DOI: 10.1016/j.ultsonch.2012.02.008

Chung K.T., Stevens S.E. y Cerniglia C.E. (1992). The reduction of azo dyes by the intestinal microflora. Crit. Rev. Microbiol. 18 (3), 175-190. DOI: $10.3109 / 10408419209114557$

Collier S.W., Storm, J.E. y Bronaugh J.L. (1993). Reduction of azo dyes during in vitro percutaneous absorption. Toxicol. Appl. Pharm. 118 (1), 73-79.

DOI: $10.1006 /$ taap.1993.1011

Crini G. (2006). Non-conventional low-cost adsorbents for dye removal: a review. Bioresource Technol. 97 (9), 1061-1065. DOI: 10.1016/j.biortech.2005.05.001

Cui P., Chen Y. y Chen G. (2011). Degradation of low concentration methyl orange in aqueous solution through sonophotocatalysis with simultaneous recovery of photocatalyst by ceramic membrane microfiltration. Ind. Eng. Chem. Res. 50, 3947-3954.

DOI: $10.1021 /$ ie 100832 q

Demirbas A. (2009). Agricultural based activated carbons for the removal of dyes from aqueous solutions: a review. J. Hazard. Mater. 167 (1-3), 1-9.

DOI: $10.1016 /$ j.jhazmat.2008.12.114

Dutta S., Ghosh A., Moi S.C. y Saha R. (2015) Application of response surface methodology for optimization of reactive azo dyes degradation process by Fenton's oxidation. IJESD 6 (11), 818-823.

DOI: $10.7763 /$ ijesd.2015.v6.705

Eren Z. e Ince N.H. (2010). Sonolitic and sonocatalytic degradation of azo dyes by low and high frequency ultrasound. J. Hazard. Mater. 177, 1019-1024.

DOI: $10.1016 /$ j.jhazmat.2010.01.021

Eren Z. (2012). Ultrasound as a basic and auxiliary process for dye remediation: A review. J. Environ. Manage. 104, 127-141. DOI: 10.1016/j.jenvman.2012.03.028

Essadki A.H., Bennajah M., Gourich B., Vial C., Azzi M. y Delmas H. (2008). Electrocoagulation/electroflotation in an external-loop airlift reactor - Application to the decolorization of textile dye wastewater: A case study. Chem. Eng. Process. 47 (8), 1211-1223.

DOI: 10.1016/j.cep.2007.03.013

Eyvaz M., Kirlaroglu M., Aktas T.S. y Yuksel E. (2009). The effects of alternating current electrocoagulation on dye removal from aqueous solutions. Chem. Eng. J. 153 (1-3), 16-22. DOI: 10.1016/j.cej.2009.05.028

Fang R., Cheng X. y Xu X. 2010. Synthesis of lignin-base cationic flocculant and its application in removing anionic azo-dyes from simulated wastewater. Bioresource Technol. 101 (19), 7323-7329.

DOI: 10.1016/j.biortech.2010.04.094

Ghodbane H. y Hamdaoui O. (2009). Intensification of sonochemical decolorization of anthraquinonic dye 
Acid Blue 25 using carbon tetrachloride. Ultrason. Sonochem. 16, 455-461.

DOI: $10.1016 /$ j.ultsonch.2008.12.005 z

Gnumeric (2014) The Gnumeric spreadsheet (version 1.12.17) [en línea]. http://www.gnumeric.org 21/11/2018

Gogate P.R. (2008). Cavitational reactor for process intensification of chemical processing applications: A critical review. Chem. Eng. Process. 47, 515-527. DOI: 10.1016/j.cep.2007.09.014

Gomathi-Devi I., Girish - Kumar S., Mohan - Reddy K. y Munikrishnappa C. (2009). Photo degradation of methyl orange an azo dye by advanced Fenton process using zero valent metallic iron: Influence of various reaction parameters and its degradation mechanism. J. Hazard. Mater. 164, 459-467.

DOI: $10.1016 /$ j.jhazmat.2008.08.017

Grassi E., Scodeller P., Filiel N., Carballo R. y Levin L. (2011). Potential of Trametes trogii culture fluids and its purified laccase for the decolorization of different types of recalcitrant dyes without the addition of redox mediators. Int. Biodeter. Biodegr. 65, 635-643.

DOI: 10.1016/j.ibiod.2011.03.007

Greluk M. y Hubicki Z. (2013). Evaluation of polystyrene anion exchange resin for removal of reactive dyes from aqueous solutions. Chem. Eng. Res. Des. 91, 13431351. DOI: 10.1016/j.cherd.2013.01.019

Guettai N. y Amar H.A. (2005). Photocatalytic oxidation of methyl orange in presence of titanium dioxide in aqueous suspension. Part II: kinetics study. Desalination 185, 439-448. DOI: 10.1016/j.desal.2005.04.049

Guivarch E., Trevin S., Lahitte C. y Oturan M.A. (2003). Degradation of azo dyes in water by Electro-Fenton process. Environ. Chem. Lett. 1, 38-44.

DOI: $10.1007 / \mathrm{s} 10311-002-0017-0$

Guo W., Shi Y., Wang H., Yang H. y Zhang G. (2010). Intensification of sonochemical degradation of antibiotics levofloxacin using carbon tetrachloride. Ultrason. Sonochem. 17, 680-684.

DOI: 10.1016/j.ultsonch.2010.01.004

Guo W., Yang Z., Zhou X.J. y Wu Q. (2015). Degradation and mineralization of dyes with advanced oxidation processes (AOPs): A brief review. Memorias. International Forum on Energy, Environment Science and Materials. Shenzhen, China. 25 al 26 de setiembre, 2015, pp. 341-344. DOI: 10.2991/ifeesm-15.2015.64

Haji S., Benstaali B. y al-Bastaki N. (2011). Degradation of methyl orange by $\mathrm{UV} / \mathrm{H}_{2} \mathrm{O}_{2}$ advanced oxidation process. Chem. Eng. J. 168, 134-139.

DOI: $10.1016 /$ j.cej.2010.12.050

Hakamada M., Matsuzawa T. y Mabuchi M. (2014). Fabrication and catalytic decoloration capacity of nanodendritic metals. Mater. Trans. 55 (3), 534-538. DOI: 10.2320/matertrans.MBW201310
Hernández J.M., García L.A., García R., Cueto A. y Carmona J.A. (2012). Estudio cinético de la fotodegradación del naranja de metilo en presencia de $\mathrm{TiO}_{2}$ : efecto de la fuente de radiación U.V., concentración del azocolorante y del catalizador. Av. Cienc. Ing. 3 (2), 25-34.

Jagruti B. (2015). Evaluation of azo dyes toxicity using some haematological and histopathological alterations in fish Catla catla. Int. J. Biol. Biomol. Agric. Food Biotech. Eng. 9 (5), 458-461. DOI: $10.1999 / 1307-6892 / 24396$

Joshi S.M., Inamdar S.A., Telke A.A., Tamboli D.P. y Govindwar S.P. (2010). Exploring the potential of natural bacterial consortium to degrade mixture of dyes and textile effluent. Int. Biodeter. Biodegr. 64, 622-628. DOI: 10.1016/j.ibiod.2010.07.001

Kalra S.S., Mohan S., Sinha A. y Singh G. (2011). Advanced oxidation processes for treatment of textile and dye wastewater: a review. Memorias. International Conference on Environmental Science and Technology. Singapur. 26 al 28 de febrero, 2011. pp. 271-275

Karcher S., Kornmüller A. y Jekel M. (2002). Anion exchange resins for removal of reactive dyes from textile wastewaters. Water Res. 36, 4717-4724.

DOI: 10.1016/s0043-1354(02)00195-1

Karthikeyan K., Nanthakumar K., Shanthi K. y Lakshmanaperumalsamy P. (2010). Response surface methodology for optimization of culture conditions for dye decolorization by a fungus, Aspergillus niger HM11 isolated from dye affected soil. Iran J. Microbiol. 2 (4), 213-222

Kaushik P. y Malik A. (2009). Fungal dye decolourization: recent advances and future potential. Environ. Int. 35 (1), 127-141. DOI: 10.1016/j.envint.2008.05.010

Khehra M.S., Saini H.S., Sharma D.K., Chadha B.S. y Chimni S.S. (2005). Comparative studies on potential of consortium and constituent pure bacterial isolates to decolorize azo dyes. Water Res. 39, 5135-5141. DOI: $10.1016 /$ j.watres.2005.09.033

Kieffer L.A., de la Sierra P.M., Devercelli M., Luna J.A., Claret M. y Leiz E. (2015). Ensayos en laboratorio para el control de floraciones algales mediante ultrasonido. Ciencia, Docencia y Tecnología 26 (50), 224-243

Kodom T., Amouzou E., Djaneye-Bo G. y Moctar-Bawa L. (2012). Photocatalytic discoloration of methyl orange and indigo carmine on $\mathrm{TiO}_{2}$ (P25) deposited on conducting substrates: Effect of $\mathrm{H}_{2} \mathrm{O}_{2}$ and $\mathrm{S}_{2} \mathrm{O}_{8}$. Int. J. Chem. Technol. 4 (2), 45-56. DOI: $10.3923 /$ ijct.2012.45.56

Konstantinou I.K. y Albanis T.A. (2004). $\mathrm{TiO}_{2}$-assisted photocatalytic degradation of azo dyes in aqueous solution: kinetic and mechanistic investigations. A review. Appl. Catal. B-Environ. 49, 1-14.

DOI: 10.1016/j.apcatb.2003.11.010 
Koohestani H. y Sadrnezhaad S. K. (2016). Photocatalytic degradation of methyl orange and cyanide by using $\mathrm{TiO}_{2} / \mathrm{CuO}$ composite. Desalin. Water Treat. 57 (46), 22029-22038. DOI: 10.1080/19443994.2015.1132395

Kumar A. y Pandey G. (2017). A review on the factors affecting the photocatalytic degradation of hazardous materials. Material Sci. Eng. Int. J. 1 (3), 106-114. DOI: 10.15406/mseij.2017.01.00018

Levin L., Melignani E. y Ramos A.M. (2010). Effect of nitrogen sources and vitamins on ligninolytic enzyme production by some white-rot fungi. Dye decolorization by selected culture filtrates. Bioresource Technol. 101 (12), 4554-4563.

DOI: $10.1016 /$ j.biortech.2010.01.102

Lim S.L., Chu W.L. y Phang S.M. (2010). Use of Chlorella vulgaris for bioremediation of textile wastewater. Bioresource Technol. 101 (19), 7314-7322.

DOI: 10.1016/j.biortech.2010.04.092

Madhavan J., Grieser F. y Ashokkumar M. (2010). Degradation of orange- $\mathrm{G}$ by advanced oxidation processes. Ultrason. Sonochem. 17, 338-343.

DOI: $10.1016 /$ j.ultsonch.2009.10.008

Mahamuni N.N. y Adewuyi Y.G. (2010). Advanced oxidation processes (AOPs) involving ultrasound for wastewater treatment: A review with emphasis on cost estimation. Ultrason. Sonochem. 17, 990-1003.

DOI: 10.1016/j.ultsonch.2009.09.005

Marci G., Augugliaro V., Bianco P. A., Baiocchi C., Garcia-Lopez E., Loddo V., Palmisano L., Pramauro E. y Schiavello M. (2003). Photocatalytic oxidation of methyl-orange in aqueous suspension: Comparison of the performance of different polycrystalline titanium dioxide. Ann. Chim - Rome 93 (7-8), 639-648

Matouq M., Al-Anber Z., Susumu N., Tagawa T. y Karapanagioti H. (2014). The kinetic of dyes degradation resulted from food industry in wastewater using high frequency of ultrasound. Sep. Purif. Technol. 135, 4247. DOI: 10.1016/j.seppur.2014.08.002

Ali S.A. y Abdullah A.Z. (2011). Sonocatalytic degradation of methyl orange dye in aqueous effluents. Memorias. International Conference on Environment and Industrial Innovation. Kuala Lumpur, Malaysia. 4 al 5 de junio, 2011, pp. 296-302

Modi H.A., Rajput G. y Ambasana C. (2010). Decolorization of water soluble azo dyes by bacterial cultures, isolated from dye house effluent. Bioresour. Technol. 101, 6580-6583. DOI: 10.1016/j.biortech.2010.03.067

Moghaddam S.S., Moghaddam M.R.A. y Arami M. (2010). Coagulation / flocculation process for dye removal using sludge from water treatment plant: Optimization through response surface methodology. J. Hazard. Mater. 175 (1-3), 651-657. DOI: $10.1016 /$ j.jhazmat.2009.10.058
Mounguengui S., Atteke C., Saha T. J., Ndikontar M.K., Dumarcay S. y Gerardin P. (2014). Discoloration and biodegradation of two dyes by white-rot fungi Perenniporia tephropora MUCL 47500 isolated in Gabon. Int. J. Curr. Microbiol. App. Sci. 3 (6), 731-741.

Mui E.L., Cheung W.H., Valix M. y McKay G. (2010). Dye adsorption onto activated carbons from tyre rubber waste using surface coverage analysis. J. Colloid Interf. Sci. 347 (2), 290-300. DOI: 10.1016/j.jcis.2010.03.061

Novotny C., Dias N., Kapanen A., Malachova K., Vandrovcová M., Itavaara M. y Lima N. (2006). Comparative use of bacterial, algal and protozoan test to study toxicity of azo- and anthraquinone dyes. Chemosphere 63, 1436-1442. DOI: 10.1016/j.chemosphere.2005.10.002

Okitsu K., Kawasaki K., Nanzai B., Takenaka N. y Bandow H. (2008). Effect of carbon tetrachloride on sonochemical decomposition of methyl orange in water. Chemosphere 71, 36-42.

DOI: $10.1016 /$ j.chemosphere.2007.10.056

Omar H.H. (2008). Algal decolorization and degradation of monoazo and diazo dyes. Pak. J. Biol. Sci. 11 (10), 1310-1316. DOI: $10.3923 /$ pjbs.2008.1310.1316

Paniwnyk L., Larpparisudthi O. y Mason T.J. (2010). Degradation of water pollutants using ultrasound. Memorias. Proceedings of 20th International Congress on Acoustics. Sydney, Australia. 23 al 27 de agosto, 2010, pp. 1-4

Pang Y.L., Abdullah A.Z. y Bhatia S. (2011). Review on sonochemical methods in the presence of catalysts and chemical additives for treatment of organic pollutants in wastewater. Desalination 277, 1-14.

DOI: $10.1016 /$ j.desal.2011.04.049

Pang X. y Song M. (2012). Study on the discolored thermodynamics and kinetics of methyl orange on expanded graphite loaded with titania. Int. J. Chem. Tech. Res. 4 (1), 346-355.

Paszczynski A., Pasti-Grigsby M.B., Goszczynski S., Crawford R.L. y Crawford D.L. (1992). Mineralization of sulfonated azo dyes and sulfanilic acid by Phanerochaete chrysosporium and Streptomyces chromofuscus. Appl. Environ. Microb. 58 (11), 3598-3604.

Peralta-Zamora P., Kunz A., Gomes de Moraes S., Pellegrini R., Campos - Moleiro P., Reyes J. y Durán N. (1999). Degradation of reactive dyes I. A comparative study of ozonation, enzymatic and photochemical processes. Chemosphere 38 (4), 835-852.

DOI: 10.1016/s0045-6535(98)00227-6

Phugare S.S., Kalyani D.C., Patil A.V. y Jadhav J.P. (2011). Textile dye degradation by bacterial consortium and subsequent toxicological analysis of dye and dye metabolites using cytotoxicity, genotoxicity and oxidative stress studies. J. Hazard Mater. 186 (1), 713-723. DOI: $10.1016 /$ j.jhazmat.2010.11.049 
Purbaningtias T. E., Wiyantoko B., Kurniawati P. y Ruwindya Y. (2015). Removal of methyl orange in aqueous solution using rice husk. Memorias. 1er International Seminar on Chemical Education. Yakarta, Indonesia. 30 de setiembre, 2015, pp. 241-246.

Rajaguru P., Fairbairn L.J., Ashby J., Willington M.A., Turner S., Woolford L.A., Chinnasamy N. y Rafferty J.A. (1999). Genotoxicity studies on the azo dye Direct Red 2 using the in vivo mouse bone marrow micronucleus test. Mutat. Res. 444, 175-180.

DOI: 10.1016/s1383-5718(99)00081-9

Rauf M.A. y Ashraf S.S. (2009). Fundamental principles and application of heterogeneous photocatalytic degradation of dyes in solution. Chem. Eng. J. 151, 10-18. DOI: $10.1016 /$ j.cej.2009.02.026

Robinson T. y Nigam P. (2008). Remediation of textile dye waste water using a white-rot fungus Bjerkandera adusta through solid-state fermentation (SSF). Appl. Biochem. Biotech. 151 (2-3), 618-628.

DOI: $10.1007 / \mathrm{s} 12010-008-8272-6$

Royer B., Cardoso N.F., Lima E.C., Ruiz V.S.O., Macedo T.R. y Airoldi C. (2009). Organofunctionalized kenyaite for dye removal from aqueous solution. J. Colloid. Interf. Sci. 336, 398-405.

DOI: $10.1016 /$ j.jcis.2009.04.025

Sanghi R., Bhattacharya B. y Singh V. (2007). Seed gum polysaccharides and their grafted co-polymers for the effective coagulation of textile dye solutions. React. Funct. Polym. 67 (6), 495-502.

DOI: 10.1016/j.reactfunctpolym.2007.02.012

Saratale R.G., Saratale G.D., Chang J.S. y Govindwar S.P. (2011). Bacterial decolorization and degradation of azo dyes: a review. J. Taiwan Inst. Chem. E. 42, 138-157. DOI: $10.1016 /$ j.jtice.2010.06.006

Scilab (2017). Scilab enterprise (versión 6.0.1) [en línea]. https://www.scilab.org 21/11/2018

Shu H.Y. y Huang C.R. (1995). Degradation of commercial azo dyes in water using ozonation and UV enhanced ozonation process. Chemosphere 31 (8), 3813-3825.

DOI: 10.1016/0045-6535(95)00255-7

Sigma-Aldrich (2004). Material safety data sheet [en línea]. http://www.glue.umd.edu/ choi/MSDS/SigmaAldrich/METHYL\%20ORANGE.pdf 21/11/2018

Suresh P., Umabala A.M. y Prasada-Rao A.M. (2015). Rapid sun light degradation of rhodamine-B, methylene blue, methyl orange, congo red and their binary mixtures using suprastoichiometric bi - molybdate. Int. J. Eng. Appl. Sci. 2 (8), 2994-3661

Tang C.W. (2013). Study of photocatalytic degradation of methyl orange on different morphologies of $\mathrm{ZnO}$ catalysts. Mod. Res. Catal. 2 (2), 19-24.

DOI: $10.4236 / \mathrm{mrc} .2013 .22003$
Tehrani-Bagha A.R., Mahmoodi N.M. y Menger F.M. (2010). Degradation of a persistent organic dye from colored textile wastewater by ozonation. Desalination 260, 34-38. DOI: 10.1016/j.desal.2010.05.004

Thompson L.H. y Doraiswamy L.K. (1999). Sonochemistry: science and engineering. Ind. Eng. Chem. Res. 38 (4), 1215-1249. DOI: $10.1021 / \mathrm{ie} 9804172$

TTI (2016). Safety data sheet. Taylor Technologies Inc. [en línea]. https://www.taylortechnologies.com/en/Image/ GetDocument/20 21/11/2018

Umbuzeiro G.A., Freeman H., Warren S.H., Kummrow F. y Claxton L.D. (2005). Mutagenicity evaluation of the commercial product CI Disperse Blue 291 using different protocols of the Salmonella assay. Food Chem. Toxicol. 43, 49-56. DOI: 10.1016/j.fct.2004.08.011

Urmi S.A., Kurny A.S.W. y Gulshan F. (2015). Decolorization of methyl orange using mill scale by photo-Fenton reaction. Procedia Eng. 105, 844-851.

DOI: 10.1016/j.proeng.2015.05.100

Wang J., Guo B., Zhang X., Zhang Z., Han J. y Wu J. (2005). Sonocatalytic degradation of methyl orange in the presence of $\mathrm{TiO} 2$ catalysts and catalytic activity comparison of rutile and anatase. Ultrason. Sonochem. $12,331-337$.

DOI: 10.1016/j.ultsonch.2004.05.002

Wang L., Zhu L., Luo W., Wu Y. y Tang H. (2007). Drastically enhanced ultrasonic decolorization of methyl orange by adding $\mathrm{CCl}_{4}$. Ultrason. Sonochem. 14, 253258. DOI: 10.1016/j.ultsonch.2006.05.004

Wang H., Niu J., Long X. y He Y. (2008). Sonophotocatalytic degradation of methyl orange by nano-sized $\mathrm{Ag} / \mathrm{TiO}_{2}$ particles in aqueous solutions. Ultrason. Sonochem. 15, 386-392.

DOI: $10.1016 /$ j.ultsonch.2007.09.011

Wang S. (2008). A comparative study of Fenton and Fenton-like reaction kinetics in decolourisation of wastewater. Dyes Pigm. 76, 714-720.

DOI: 10.1016/j.dyepig.2007.01.012

Wang F., Zhang H., Chen Z., Zhang M. y Zhang L. (2011). Kinetics and possible mechanism of the degradation of methyl orange by microwave assisted with Fenton reagent. Memorias. 5th International Conference on Bioinformatics and Biomedical Engineering. Wuhan, Hubei, China. 10 al 12 de mayo, 2011, pp. 1-4.

DOI: $10.1109 /$ icbbe. 2011.5781008

Wang S., Sugamori K.S., Breneman D., Hsu I., Calce A. y Grant D.M. (2012). Influence of arylamine N-acetyltransferase, sex, and age on 4-aminobiphenil-induced in vivo mutant frequencies and spectra in mouse liver. Environ. Mol. Mutagen. 53, 350-357.

DOI: $10.1002 / \mathrm{em} .21695$

Wang X., Wang L.G., Li J.B., Qiu J.J., Cai C. y Zhang H. (2014). Degradation of Acid Orange 7 by persulfate 
activated with zero valent iron in the present of ultrasonic irradiation. Sep. Purif. Technol. 122, 41-46. DOI: 10.1016/j.seppur.2013.10.037

Wang Y., Gai L., Ma W., Jiang H., Peng X. y Zhao L. (2015). Ultrasound-assisted catalytic degradation of methyl orange with $\mathrm{Fe}_{3} \mathrm{O}_{4}$ /polyaniline in near neutral solution. Ind. Eng. Chem. Res. 54, 2279-2289.

DOI: $10.1021 /$ ie $504242 \mathrm{k}$

Wang Z., Ai L., Huang Y., Zhang J., Li S., Chen J. y Yang F. (2017). Degradation of azo dye with activated peroxygens: when zero-valent iron meets chloride. RSC Adv. 7, 30941-30948. DOI: 10.1039/c7ra03872k

Wu J., Doan H. y Upreti S. (2008). Decolorization of aqueous textile reactive dye by ozone. Chem. Eng. J. 142, 156-160. DOI: 10.1016/j.cej.2007.11.019

Wu J., Zhang H. y Qiu J.J. (2012). Degradation of Acid Orange 7 in aqueous solution by a novel electro/Fe2+/ peroxydisulfate process. J. Hazard. Mater. 215-216, 138-145. DOI: 10.1016/j.jhazmat.2012.02.047

Yang S., Jin R., He Z., Qiao Y. y Liu X (2017). Degradation of methyl orange using hydrodynamic cavitation technology combined with chlorine dioxide oxidation: optimization using box-behnken design (BBD), Chem. Eng. Trans. 59, 1063-1068. DOI: $10.3303 /$ CET1759178

Youssef N.A., Shaban S.A., Ibrahim S.A. y Mahmoud S.A. (2016). Degradation of methyl orange using Fenton catalytic reaction. Egypt. J. Pet. 25, 317-321.

DOI: $10.1016 /$ j.ejpe.2015.07.017
Yuan N., Zhang G., Guo S. y Wan Z. (2016). Enhanced ultrasound-assisted degradation of methyl orange and metronidazole by rectorite-supported nanoscale zerovalent iron. Ultrason. Sonochem. 28, 62-68. DOI: 10.1016/j.ultsonch.2015.06.029

Zhang H., Duan L. y Zhang D. (2006). Decolorization of methyl orange by ozonation in combination with ultrasonic irradiation. J. Hazard. Mater. 138 (1), 53-59. DOI:10.1016/j.jhazmat.2006.05.034

Zhao H., Zhang G. y Zhang Q. (2014). $\mathrm{MnO}_{2} / \mathrm{CeO}_{2}$ for catalytic ultrasonic degradation of methyl orange. Ultrason. Sonochem. 21 (3), 991-996.

DOI: 10.1016/j.ultsonch.2013.12.002

Zhiyong Y., Keppner H., Laub D., Mielezarski E., Mielezarski J., Kiwi-Minsker L., Renken A. y Kiwi J. (2008). Photocatalytic discoloration of Methyl Orange on innovative parylene- $\mathrm{TiO}_{2}$ flexible thin films under simulated sunlight. Appl. Catal. B-Environ. 79 (1), 63-71. DOI: 10.1016/j.apcatb.2007.10.006

Zhong J. (2013). Photocatalytic decolorization of methyl orange solution with phosphotungstic acid. Iran. J. Chem. Chem. Eng. 32 (1), 57-65.

Zyoud A., Zu'bi A., Helal M.H.S., Park D., Campet G. y Hilal H.S. (2015). Optimizing photo-mineralization of aqueous methyl orange by nano- $\mathrm{ZnO}$ catalyst under simulated natural conditions. J. Environ. Health Sci. 13, 1-10. DOI: 10.1186/s40201-015-0204-0 